\title{
Role of lactate dehydrogenase and other biomarkers in predicting prognosis of community-acquired pneumonia
} Rasha M. Hendy ${ }^{\mathrm{a}}$, Mona A. Elawady ${ }^{\mathrm{b}}$, Heba M. Abd EL Kareem ${ }^{\mathrm{c}}$

\begin{abstract}
Background An increase in serum lactate dehydrogenase (LDH) activity is commonly taken to support the presumptive diagnosis of some lung diseases and a variety of extrapulmonary disorders, but the role of LDH as an early prognostic factor in detecting outcome in patients with community acquired pneumonia (CAP) was not well studied before.
\end{abstract}

Aim To assess the prognostic value of $\mathrm{LDH}$ and other laboratory markers [C-reactive protein (CRP), serum albumin, and neutrophil percentage] in patients with CAP.

Patients and methods We compared levels of LDH and other laboratory markers (CRP, serum albumin, and neutrophil percentage) with each other and with CURB65 score, length of hospital stay, and worse outcomes (ICU admission, mechanical ventilation, and mortality) in 62 (33 males and 29 females) patients with CAP who were admitted to Pulmonology Department, Benha University Hospital, between March 2016 and March 2017 after ethical committee approval.

\section{Introduction}

Community-acquired pneumonia (CAP) is a very common cause for hospital admission, with potentially life-threatening complications, which may occur particularly in the elderly and those with underlying health problems. These complications may include, empyema, lung abscess, acute respiratory distress syndrome, sepsis, and worsening of underlying health problems. Despite advances in diagnosis and treatment, CAP remains a common, potentially fatal disease associated with significant morbidity, mortality, and health care expenditure [1]. Overall annual incidence is $\sim 1600 / 100000$ in the USA and 1100/100 000 in Europe, with 250 of 100000 patients requiring hospitalization [2]. Although mortality associated with CAP is below $5 \%$ among outpatients, it can be as high as $10 \%$ among inpatients and can exceed 30\% among patients admitted to the ICU [3].

In patients with CAP requiring ICU admission, mortality may involve more than half of these patients compared with $4-18 \%$ mortality in ward admission and only less than $1 \%$ who do not need hospitalization [4]. Identifying patients at high risk of mortality could substantially improve their treatment and management [5]. The stratification of the severity and prognosis of CAP is a vital feature as it is one of the most common causes of mortality among other infectious diseases in the developed countries [6]. To
Results Most of the patients with worse outcomes showed significant high levels of LDH, CRP, albumin, and neutrophil percentage early on admission.

Conclusion LDH was a highly sensitive biomarker for early prediction of worse outcomes in patients with CAP.

Egypt J Bronchol 2019 13:539-544

(C) 2019 Egyptian Journal of Bronchology

Egyptian Journal of Bronchology 2019 13:539-544

Keywords: community-acquired pneumonia, lactate dehydrogenase, prognosis

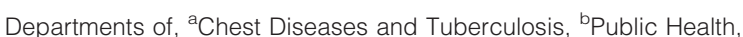
Community Medicine, 'Biochemistry, Benha Faculty of Medicine, Benha University, Banha, Egypt

Correspondence to Rasha M. Hendy, Dectorate and lecturer of chest Disease in Benha University, Chest Department, Benha University Hospital, Banha, 13518, Egypt. Mob: 01028340748 ; e-mail: rashahendy97@yahoo.com

Received: 6 March 2019 Revised: 20 June 2019 Accepted: 16 July 2019 Published: 25 October 2019

improve the outcomes in the management of CAP, there has recently been a significant attention to the use of evidence-based scoring systems and biological markers to predict treatment failure, justify hospital admission in either acute medical settings or ICU, and also to classify the disease severity, which will help in predicting the mortality rate [7].

\section{Aim}

To detect role of lactate dehydrogenase (LDH), Creactive protein $(\mathrm{CRP})$, serum albumin, and neutrophil percentage in predicting prognosis of CAP.

\section{Patients and methods}

This cross-sectional study was conducted on 62 adult patients who were admitted in Pulmonology Department, Benha University Hospital, from March 2016 to March 2017, diagnosed as having CAP based on clinical and radiological evidence. At first, consents from patients with diagnosis of CAP to participate in the study were taken. Patients having other conditions that can cause increase in LDH like

This is an open access journal, and articles are distributed under the terms of the Creative Commons Attribution-NonCommercial-ShareAlike 4.0 License, which allows others to remix, tweak, and build upon the work non-commercially, as long as appropriate credit is given and the new creations are licensed under the identical terms. 
myocardial infarction, liver disease, lymphoma, HIV, pancreatitis, and hemolytic anemia were excluded.

A bundle of measures were performed within the first $3 \mathrm{~h}$ of admission, including serum LAH (done by semiautomated analyzer photometer 4010; RIELE, Robert Riele and CO, Berlin, Germany), CRP (done by latex agglutination; CRP-Latex cromatest, Biotrax Testing, Biotrax testing Laboratory INC, Cheektowaga, Newyork, USA), serum albumin, kidney and liver functions (done by Biosystems A15 auto-analyzer, Barcelona, Spain), and $\mathrm{CBC}$ with differential (done by automated hematology system; Sysmex XE-5000Analyzer; Sysmex America Inc., SYSMEX, Ramsey, MN, USA). CURB65 score (which is a well validated severity score for predicting severity and mortality from pneumonia) was assessed for all studied patients according to the following criteria: confusion, blood urea nitrogen (BUN), respiratory rate, blood pressure, and age of at least 65 years old [7]. Initiation of appropriate empirical broad-spectrum intravenous antibiotics was done. Treatment with intravenous crystalloids was given if indicated.

Patients with the following criteria were excluded from this study: tuberculosis, bronchiectasis, HIV infection, and solid organ or hematological malignancies. Patients admitted to hospital in the previous 14 days or with nursing home residents were also excluded.

The following criteria were considered as indicators for worse outcome in our studied group of patients: admission in the ICU, mechanical ventilation (MV), and death. All data were collected after ethical committee approval.

\section{Statistical analysis [8]}

The collected data tabulated and analyzed using SPSS version 16 software (SPSS for Windows, version 16.0; SPSS Inc., Chicago, Illinois, USA). Data were presented using $\chi^{2}$-test to analyze them. Correlation coefficient was used to find relation between $\mathrm{LDH}$ and other variables. Quantitative data were presented as a mean ${ }_{ \pm} \mathrm{SD}$. Students $t$-test and Mann-Whitney test were used to compare means of different groups of parametric and nonparametric data, assuming normality at $P$ more than 0.05 . $P$ value less than 0.05 is significant, $P$ value more than 0.05 is nonsignificant, and $P$ value up to 0.001 is highly significant.

\section{Results}

This study was carried out on 62 (33 males and 29 females) patients with CAP who were admitted to
Pulmonology Department, Benha University Hospital, between March 2016 to March 2017. Their ages were 29-86 years (mean 53.4 \pm 12.57 ), and 33 patients were smokers. More than half of the studied group experienced hypertension (55.0\%), 40.0\% had DM, and 20.0\% had asthma. Ten (16.1\%) patients were admitted to ICU owing to severe condition; three of them were $\mathrm{MV}$ and two died. However, the other $52(83.9 \%)$ patients were treated in the ordinary ward. The median hospital stay was 4 days, and interquartile range (IQR) ranged from 3 to 5 days (Table 1 ).

Serum LDH ranged from 266 to 1424 U/1, with mean \pm SD of $598.1 \pm 286.79 \mathrm{U} / 1$. Serum CRP in patients had IQR from 22.75 to $202.25 \mathrm{mg} / 1$, with a median value of $53.5 \mathrm{mg} / 1$. Neutrophils\% ranged from 49.4 to $84.5 \%$, with a mean $\pm S D$ value of $63.23 \pm 15.99 \%$, whereas

Table 1 Characteristic features of the studied group

\begin{tabular}{|c|c|}
\hline & $N=62$ \\
\hline Age [mean \pm SD (range)] & $53.42 \pm 12.57(29-86)$ \\
\hline \multicolumn{2}{|l|}{$\operatorname{Sex}[n(\%)]$} \\
\hline Male & $33(53.2)$ \\
\hline Female & $29(46.8)$ \\
\hline \multicolumn{2}{|l|}{ Smoking } \\
\hline Yes & $33(53.2)$ \\
\hline No & $29(46.8)$ \\
\hline \multicolumn{2}{|l|}{ Comorbidities [9] } \\
\hline DM & $8(40.0)$ \\
\hline HTN & $11(55.0)$ \\
\hline Asthma & $4(20.0)$ \\
\hline LVH & $1(5.0)$ \\
\hline PHTN & $2(10.0)$ \\
\hline MS & $2(10.0)$ \\
\hline \multicolumn{2}{|l|}{ Comorbidities } \\
\hline DM and HTN & $4(6.5)$ \\
\hline Asthma & $3(4.8)$ \\
\hline DM & $3(4.8)$ \\
\hline HTN and LVH & $1(1.6)$ \\
\hline DM and asthma & $1(1.6)$ \\
\hline HTN & $6(9.7)$ \\
\hline PHTN and MS & $2(3.2)$ \\
\hline No & $42(67.7)$ \\
\hline Hospital stay [median (IQR)] & $4(3-5)$ \\
\hline \multicolumn{2}{|l|}{ ICU admission [n (\%)] } \\
\hline Yes & $10(16.1)$ \\
\hline No & $52(83.9)$ \\
\hline \multicolumn{2}{|l|}{ MV } \\
\hline Yes & $3(4.8)$ \\
\hline No & $59(95.2)$ \\
\hline \multicolumn{2}{|l|}{ Mortality } \\
\hline Yes & $2(3.2)$ \\
\hline No & $60(96.8)$ \\
\hline
\end{tabular}

DM, diabetes mellitus; HTN, hypertension; IQR, interquartile range; LVH, left ventricular hypertrophy; MS, mitral stenosis; MV, mechanical ventilation; PHTN, pulmonary hypertension. 
albumin ranged from 1.8 to $6.0 \mathrm{mg} / \mathrm{dl}$, with a mean $\pm \mathrm{SD}$ value of $3.64 \pm 0.67$ (Table 2 ).

Table 3 illustrated significant direct correlation between neutrophils LDH and CRP with each other and with CURB65 and hospital stay, whereas they showed significant negative correlation with serum albumin. Moreover, serum albumin showed significant negative correlation with CURB65 and hospital stay.

Table 4 illustrates a significant relation between neutrophil\% $(P=0.003)$, serum LDH $(P=0.001)$, $\operatorname{CRP}(P=0.008)$, and low albumin $(P=0.001)]$ with worse outcomes (ICU admission, MV, and mortality).

ROC analysis showed that cutoff value of neutrophil\% in predicting worse outcomes (ICU admission, MV, and mortality) was $66.4 \%$, with sensitivity of $76.9 \%$ and specificity of $63.3 \%$. Cutoff value of LDH in predicting the worse outcomes was $511 \mathrm{U} / 1$, with sensitivity of

Table 2 Mean values of laboratory markers in the studied patients

\begin{tabular}{lc}
\hline Laboratory markers & Values \\
\hline $\mathrm{LDH}[$ mean $\pm \mathrm{SD}($ range $)]$ & $598.1 \pm 286.79(266-1424)$ \\
$\mathrm{CRP}[$ median $(\mathrm{IQR})]$ & $53.5(22.75-202.25)$ \\
Albumin [mean $\pm \mathrm{SD}($ range)] & $3.64 \pm 0.67(1.8-6.0)$ \\
Neutrophils\% [mean $\pm \mathrm{SD}$ (range)] & $65.61 \pm 11.03(49.4-84.5)$ \\
\hline CRP, C-reactive protein; IQR, interquartile range; LDH, lactate \\
dehydrogenase.
\end{tabular}

$76.9 \%$ and specificity of $65.3 \%$. Cutoff value of $\mathrm{CRP}$ in predicting worse outcomes was $30 \mathrm{mg} / 1$, with sensitivity of $76.9 \%$ and specificity of $36.7 \%$, and the cutoff value of serum albumin in predicting worse outcomes was $3.55 \mathrm{mg} / \mathrm{dl}$, with sensitivity of $76.9 \%$ and specificity of $51 \%$ (Table 5).

Logistic regression showed that $\mathrm{LDH}$ was the most closely associated variable with poor outcomes (ICU admission, MV, and mortality) (Table 6).

\section{Discussion}

$\mathrm{LDH}$ has been studied in many pulmonary and nonpulmonary diseases, and high level of this marker was used as presumptive diagnosis of many pulmonary diseases, for example, tuberculosis,

Table 5 Validity of neutrophil\%, lactate dehydrogenase, Creactive protein and serum albumin in predicting worse outcomes (mortality, ICU admission and mechanical ventilation)

\begin{tabular}{lcccc}
\hline & Neutrophil\% & LDH & CRP & Albumin \\
\hline AUC & 0.755 & 0.801 & 0.739 & 0.792 \\
Cutoff point & 66.4 & 511 & 30 & 3.55 \\
Sensitivity & 76.9 & 76.9 & 76.9 & 76.9 \\
Specificity & 63.3 & 65.3 & 36.7 & 51.0 \\
PPV & 35.7 & 37.0 & 24.4 & 29.4 \\
NPV & 92.1 & 91.4 & 85.7 & 89.3 \\
Accuracy & 66.1 & 67.7 & 45.2 & 56.5 \\
\hline
\end{tabular}

AUC, area under the curve; CRP, C-reactive protein; $\mathrm{LDH}$, lactate dehydrogenase; NPV, negative predictive value; PPV, positive predictive value.

Table 3 Correlation between neutrophils, lactate dehydrogenase, C-reactive protein, and serum albumin with each other and with CURB 56 and hospital stay

\begin{tabular}{|c|c|c|c|c|c|c|c|c|}
\hline & \multicolumn{2}{|c|}{ Neutrophils } & \multicolumn{2}{|c|}{$\mathrm{LDH}$} & \multicolumn{2}{|c|}{ CRP } & \multicolumn{2}{|c|}{ Albumin } \\
\hline & $R$ & $P$ value & $r$ & $P$ value & $r$ & $P$ value & $r$ & $P$ value \\
\hline Neutrophils & & & 0.533 & $<0.001^{\star *}$ & 0.518 & $<0.001^{\star *}$ & -0.299 & $0.018^{*}$ \\
\hline $\mathrm{LDH}$ & 0.533 & $<0.001^{* *}$ & & & 0.711 & $<0.001^{\star \star}$ & -0.524 & $<0.001^{\star *}$ \\
\hline CRP & 0.518 & $<0.001^{\star *}$ & 0.711 & $<0.001^{\star *}$ & & & -0.449 & $<0.001^{\star *}$ \\
\hline Albumin & -0.549 & $<0.001^{\star *}$ & -0.52 & $<0.001^{\star *}$ & -0.449 & $<0.001^{\star \star}$ & & \\
\hline CURB 56 & 0.606 & $<0.001^{* *}$ & 0.859 & $<0.001^{* *}$ & 0.824 & $<0.001^{\star *}$ & -0.549 & $<0.001^{\star *}$ \\
\hline Hospital stay & 0.467 & $<0.001^{* *}$ & 0.855 & $<0.001^{\star *}$ & 0.632 & $<0.001^{\star *}$ & -0.475 & $<0.001^{\star *}$ \\
\hline
\end{tabular}

CRP, C-reactive protein; LDH, lactate dehydrogenase. ${ }^{*}$ Significant. ${ }^{* *}$ Highly significant.

Table 4 Relation between laboratory markers (neutrophils, lactate dehydrogenase, C-reactive protein and albumin) and worse outcomes (ICU admission, mortality, and mechanical ventilation)

\begin{tabular}{|c|c|c|c|c|c|c|c|c|c|c|c|c|}
\hline & \multicolumn{3}{|c|}{ Neutrophil } & \multicolumn{3}{|c|}{ LDH } & \multicolumn{3}{|c|}{ CRP } & \multicolumn{3}{|c|}{ Albumin } \\
\hline & $\begin{array}{l}\text { Mean } \\
\pm \text { SD }\end{array}$ & $\begin{array}{c}\text { Student } \\
t \text {-test }\end{array}$ & $\begin{array}{c}P \\
\text { value }\end{array}$ & $\begin{array}{l}\text { Mean } \\
\pm S D\end{array}$ & $\begin{array}{c}\text { Student } \\
t \text {-test }\end{array}$ & $\begin{array}{c}P \\
\text { value }\end{array}$ & $\begin{array}{l}\text { Mean } \\
\pm \text { SD }\end{array}$ & $\begin{array}{c}\text { Mann-Whitney } \\
\text { test }\end{array}$ & $\begin{array}{c}P \\
\text { value }\end{array}$ & $\begin{array}{l}\text { Mean } \\
\pm S D\end{array}$ & $\begin{array}{c}\text { Student } \\
t \text {-test }\end{array}$ & $\begin{array}{c}P \\
\text { value }\end{array}$ \\
\hline \multicolumn{13}{|c|}{ Worse outcomes } \\
\hline $\begin{array}{l}\text { Yes } \\
\text { (13) }\end{array}$ & $\begin{array}{l}73.56 \\
\pm 5.75\end{array}$ & 3.13 & $0.003^{* *}$ & $\begin{array}{l}862.08 \\
\pm 337.0\end{array}$ & $Z=3.31$ & $0.001^{* *}$ & $\begin{array}{c}213.95 \\
\pm 143.07\end{array}$ & $Z=2.64$ & $0.008^{* *}$ & $\begin{array}{c}3.08 \\
\pm 0.61\end{array}$ & 3.65 & $0.001^{\text {** }}$ \\
\hline $\begin{array}{l}\text { No } \\
(49)\end{array}$ & $\begin{array}{c}63.5 \\
\pm 11.17\end{array}$ & & & $\begin{array}{c}528.06 \\
\pm 228.59\end{array}$ & & & $\begin{array}{c}83.06 \\
\pm 87.16\end{array}$ & & & $\begin{array}{c}3.78 \\
\pm 0.61\end{array}$ & & \\
\hline
\end{tabular}

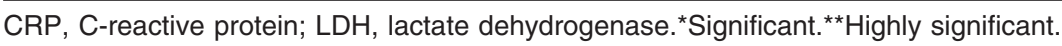


Table 6 Logestic regression to predict worse outcome

\begin{tabular}{lcccc}
\hline & Exp $(B)$ & $P$ value & \multicolumn{2}{c}{$\begin{array}{c}95 \% \mathrm{Cl} \text { for Exp } \\
(B)\end{array}$} \\
\cline { 3 - 5 } & & & Lower & Upper \\
\hline LDH & 1.906 & 0.007 & 1.002 & 2.010 \\
CRP & 0.074 & 0.101 & 0.003 & 1.663 \\
Hypoalbuminemia & 1.026 & 0.439 & 0.367 & 10.119 \\
Neutrophil\% & 0.195 & 0.169 & 0.019 & 2.004 \\
\hline
\end{tabular}

$\mathrm{Cl}$, confidence interval of odd ratio; $\mathrm{CRP}, \mathrm{C}$-reactive protein; Exp $(B)$, exponentiation of the $B$ coefficient, which is an odd ratio; $\mathrm{LDH}$, lactate dehydrogenase.

Pneumocystis carinii pneumonia, and CAP [9], and also studied in interstitial lung diseases, acute respiratory distress, and obstructive lung diseases [10].

LDH is a cytoplasmic enzyme expressed in nearly all types of cells of the body. It is released into blood when the cells experience injury or death caused by dehydration, ischemia, bacterial toxins, drugs, and chemical poisonings. Because it is expressed in various organs/tissues by high concentration, the leakage of $\mathrm{LDH}$ from even a small scale of injured tissue can result in a significantly elevated serum level. It has been used as an indicator of cellular injury induced by various etiologies [11].

Reliable prediction of patients with CAP may substantially improve patient management, timely anti-infectious therapy, and nurse intervention [12].

In a study done by Lim et al. [7], mean age was 64 years, with male percentage constituted $51.5 \%$. In another study done by Brogly et al. [11], males and females were equal. Bertsias et al. [13] found that smokers represented $41 \%$ of CAP cases. Smoking is an established risk factor for CAP, probably owing to its adverse effects on respiratory epithelium and the clearance of bacteria from the respiratory tract [14]. Calle et al. [15] showed that mean age was 60.5 years, with 51.7 of them being males. Moreover, Yang et al. [16] found that median age was 61 years, with male percentage being $66.35 \%$. Berstials et al. [13] found that $42 \%$ of patients with CAP had multimorbidity, with most frequent chronic conditions being heart diseases followed by COPD and type 2 DM. Comorbid conditions associated with an increased risk of CAP, including diabetes mellitus and impaired immune function, have previously been identified as risk factors for CAP [14].

In a study done by Ewig et al. [15], which included 92 patients with CAP, the mean age of patients was $51 \pm 19$ years (range from 15-87 years); males constituted $67.4 \%$ of them, and $45 \%$ of the patients had at least one underlying chronic disease as a risk factor for acquiring CAP [15]. Liu et al. [17] found that mean age of their studied patients with CAP was $64 \pm 19$ years, males were $59.6 \%$, and overall $37.6 \%$ of the patients were accompanied by one or more coexisting diseases (e.g. COPD and CHF).

Liu et al. [17] found in their study, median length of hospital stay was 10 days (IQR 7-15) and mortality was 8.2\%. Ewig et al. [15] found that among 92 patients with CAP, $34.8 \%$ were admitted in ICU, $14.1 \%$ were $\mathrm{MV}$, and mortality was $22 \%$. Severity of disease and comorbidity may be responsible for this wide range of reported mortality.

This study showed that serum LDH had a significant positive correlation with CURB65 score and length of hospital stay. It also significantly increased among ICU admitted, died, and MV patients. This agrees with Ewig et al. [15], who reported that increased serum LDH values were associated with increased mortality in 92 patients with CAP. They showed that higher serum LDH level indicated more severe complications and worse prognosis [15]. Moreover, previous studies done by Hoffman and Rogers [18], Schultze et al. [19], Quist and Hill [9], and Padilla et al. [20] have demonstrated that the elevated LDH in serum, bronchoalveolar lavage, and pleural fluid can help determine the extent of lung tissue damage and inflammation, such as pulmonary embolism, P. carinii pneumonia, tuberculosis, bacterial pneumonia, and influenza $A$.

Liu et al. [17] found that the expanded CURB-65 score, which extends independent risk factors to eight variables (including serum LDH, albumin and platelets) in assessing CAP severity, significantly improves identifying high-risk patients than CURB-65 and other assessment tool, through decreasing the relative weight of age and blood pressure and eliminating the use of imaging and comorbid illnesses in the calculation. They concluded that expanded CURB-65 is a relatively simpler and more effective marker in assessing the severity of hospitalized patients with CAP.

This study showed that albumin had a significant negative correlation with CURB65 and length of hospital stay, and it was significantly decreased among ICU admitted, died patients, and patients subjected to MV. Hypoalbuminemia, which can be caused by malnutrition, liver cirrhosis, or infection process, contributes to an increased mortality in hospitalized patients [21]. There is a close correlation between low serum albumin concentration and mortality in patients with CAP [22]. A study done by Liu et al. [17] showed 
that serum albumin less than $3.5 \mathrm{~g} / 1$ was significantly associated with 30 -day mortality in patients with CAP. Lee et al. [22] concluded that low serum albumin was significantly different between survivors and nonsurvivors and was associated with 28-day mortality in hospitalized patient with CAP.

This study showed that CRP had a significant positive correlation with CURB65 score and length of hospital stay, and it was increased significantly among died patients and patients subjected to MV. Similarly, Lee et al. [22] found that elevated CRP was significantly different between survivors and nonsurvivors, and that increased CRP was associated with 28-day mortality. Li et al. [23] concluded that CRP of at least four times the mean or median for the patient center was an independent predictive risk factor that correlated with adverse outcomes in elderly patients. Hohenthal et al. [24] found that high CRP levels more than $100 \mathrm{mg} / 1$ on day 4 after the admission were significantly associated with complications $(P<0.01)$. There was a trend for an association between the level of CRP on admission and the time to reach clinical stability $(P<0.01)$. They concluded that $\mathrm{CRP}$ may be valuable for revealing the development of complications in CAP. It may also be useful to assess the disease severity.

This study found that serum neutrophils increased significantly among patients admitted to ICU, and it showed significant increase among died patients and patients subjected to MV. In agreement with this study, Jose et al. found that increased neutrophil cell percentage was associated with substantial increase in the risk of mortality. They found that unlike most of the predictive markers used in clinical practice, basic blood count could provide parameters with the potential of high predictive capacity for mortality in patients with CAP, which are easy to handle and cost effective [25]. Li et al. [23] found that higher neutrophil percentage was an independent predictive risk factor that correlated with adverse outcomes.

Ewig et al. [15] showed that serum levels of LDH (with cutoff value $\geq 260 \mu / 1$, with $P=0.0154$ ), heart rate (with cutoff value $\geq 90$ beats/min and $P=0.03$ ), and systolic blood pressure (with cutoff value $\leq 80$ and $P=0.142$ ) were the variables most closely associated with fatal outcome in multivariate analysis. They found a discriminant role of these three variables to achieve high predictive value [15]. Lim et al. [7] found that serum albumin less than $30 \mathrm{~g} / \mathrm{dl}(P=0.001)$ and age of at least 65 years $(P=0.003)$ were both independably associated with 30 -day mortality. Liu and colleagues found that elevated serum LDH level $(>230 \mu / 1)$, thrombocytopenia (platelet count $<10^{5} / \mathrm{ml}$ ), and hypoalbuminemia (albumin level $<3.5 \mathrm{~g} / \mathrm{dl}$ ) were independent risk factors for death on multivariate analysis [16].

Limitations of this study included relatively small size of the studied group, and blood samples were collected as soon as patients were admitted, so there were variations in the time of collecting them.

\section{Conclusion}

$\mathrm{LDH}$, albumin, CRP, and neutrophils\% are important serum markers in determining CAP prognosis. They should be performed on admission to predict the course and probable complications in patients with CAP.

\section{Acknowledgements}

Rasha Hendy wrote the paper. Mona-Elawady did statistics of the paper. Heba Abdelkareem collected samples and performed laboratory investigations.

The manuscript has been read and approved by all the authors. Each author believes that the manuscript represents honest work.

The manuscript has been read and approved by all the authors, and the requirements for authorship have been met, and each author believes that the manuscript represents honest work.

\section{Financial support and sponsorship}

Nil.

\section{Conflicts of interest}

There are no conflicts of interest.

\section{References}

1 Musher DM, Thorner AR. Community acquired pneumonia. N Engl J Med 2014; 371:1619-1628.

2 Prina E, Ranzani OT, Torres A. Community acquired pneumonia. Lancet 2015; 386:1097-1108.

3 Wiemken TL, Peyrani P, Ramirez JA. Global changes in the epidemiology of community acquired pneumonia. Semin Respir Crit Care Med 2012; 33:213-219.

4 Falcone M, Russo A, Cangemi R, Farcomeni A, Calvieri C, Barillà F, et al. Lower mortality rate in elderly patients with community-onset pneumonia on treatment with aspirin. J Am Heart Assoc 2015; 4:e001595.

5 Restrepo MI, Mortensen EM, Rello J, Brody J, Anzueto A. Late admission to ICU in patients with community acquired pneumonia is associated with high mortality. Chest 2010; 137:552-557.

6 Restrepo MI, Mortensen EM, Velez JA, Frei C, Anzueto A. A comparative study of community-acquired pneumonia patients admitted to the ward and the ICU. Chest 2008; 133:610-617.

7 Lim WS, Van der Eerden MM, Laing R, Boersma WG, Karalus N, Town GI, et al. Defining community acquired pneumonia severity on presentation to hospital: an international derivation and validation study. Thorax 2003, 58:377-382. 
8 Kothari CR. Research methodology: methods and techniques. Second edition. New Delhi: New Age International Publishers; 2004.

9 Quist J, Hill AR. Serum lactate dehydrogenase (LDH) in Pneumocystis carinii pneumonia, tuberculosis, and bacterial pneumonia. Chest 1995; 108:415-418.

10 McFadden RG, Oliphant LD. Serum lactic dehydrogenase activity and diffuse interstitial pneumonitis. Chest 1991; 100:1182.

11 Brogly N, Devos P, Boussekey N, Georges H, Chiche A, Leroy O. Impact of thrombocytopenia on outcome of patients admitted to ICU for severe community-acquired pneumonia. J Infect 2007; 55:136-140.

12 Khan A, Woodhead M. Major advances in managing community-acquired pneumonia. F1000Prime Rep 2013; 5:43.

13 Bertsias A, Tsiligianni IG, Duijker G, Siafakas N, Lionis CH. Studying the burden of community-acquired pneumonia in adults aged $\geq 50$ years in primary health care: an observational study in rural Crete,Greece. NPJ Prim Care Respir Med 2014; 24:14017.

14 Filippidis FT, Vardavas Cl, Loukopoulou A, Behrakis P, Connolly GN, Tountas Y. Prevalence and determinants of tobacco use among adults in Greece: 4-year trends. Eur J Public Health 2013; 23:772-776.

15 Ewig S, Bauer T, Hasper E, Pizzulli L, Kubini R, Luderitz B. Prognostic analysis and predictive value for outcome of hospital-treated community acquired pneumonia. EUR Respir J 1995; 8:392-397.

16 Yang $\mathrm{T}$, Wan $\mathrm{CH}$, Wang $\mathrm{H}$, Chen JQL, Shen $\mathrm{Y}$, Wen F. The prognostic and risk-stratified value of neutrophil-lymphocyte count ratio in Chinese patients with community-acquired pneumonia. Eur J Inflam 2017; 15:22-22.

17 Liu JL, Xu F, Zhou H, Xue-Jie WU, Shi LX, Lu RQ, et al. Expanded CURB65: a new score system predicts severity of community-acquired pneumonia with superior efficiency. Sci Rep 2016; 6:22911.
18 Hoffman RM, Rogers RM. Serum and lavage lactate dehydrogenase isoenzymes in pulmonary alveolar proteinosis. Am Rev Respir Dis 1991; 143:42-46.

19 Schultze AE, Gunaga KP, Wagner JG, Hoorn CM, Moorehead WR, Roth RA. Lactate dehydrogenase activity and isoenzyme patterns in tissues and bronchoalveolar lavage fluid from rats treated with monocrotaline pyrrole. Toxicol Appl Pharmacol 1994; 126:301-310.

20 Padilla RP, Zamboni D, Leon S, Hernandez M, Falconi FQ, Bautista E, et al. Pneumonia and respiratory failure from swine-origin influenza $A$ (H1N1) in Mexico. N Engl J Med 2009; 361:680-689.

21 Herrmann FR, Safran C, Levkoff SE, Minaker KL. Serum albumin level on admission as a predictor of death, length of stay, and readmission. Arch Intern Med 1992; 152:125-130.

22 Lee JH, Kim J, Kim K, Jo YH, Rhee J, Kim TY, et al. Albumin and Creactive protein have prognostic significance in patients with communityacquired pneumonia. J Crit Care 2011; 26:287-294.

$23 \mathrm{Li}$ JS, Hou ZK, Yu XQ, Li SY, Sun ZK, Zhang W, et al. Prognostic factors for community-acquired pneumonia in middle-aged and elderly patients treated with integrated medicine. J Tradit Chin Med 2012; 32:179-186.

24 Hohenthala $U$, Hurmeb $S$, Heleniusb $H$, Heiroa $M$, Meurmanc $O$, Nikoskelainena $\mathrm{J}$, et al. Utility of $\mathrm{C}$-reactive protein in assessing the disease severity and complications of community-acquired pneumonia. Clin Microbiol Infect 2009; 15:1026-1032.

25 Curbelo J, Bueno SL, Román JMG, Gómez MO, Rajas O, Jiménez GF, et al. Inflammation biomarkers in blood as mortality predictors in community-acquired pneumonia admitted patients: importance of comparison with neutrophil count percentage or neutrophil-lymphocyte ratio. PLoS One 2017; 12:e0173947. 